\title{
An Intelligent and Adaptive Model for Change Management
}

\author{
Ali M. Alshahrani \\ Arab Open University (AOU) \\ Riyadh 11681, Saudi Arabia
}

\begin{abstract}
The continuous and rapid changes that are taking place in the world today makes the change management crucial to any organization. The existing change management models bridge the gap between motivation, planning, and implementation. These models are highly significant as the organizational change is not a rare event anymore, but it is an ongoing process, and the 'business as usual' model becomes insignificant to most organizations. To automatize the theoretical model of change management, an intelligent and adaptive model for change management is developed in this paper, which takes into consideration all the positive and negative effects (factors) that may take place at any time and any place internally (internal factors) or externally (external factors). Based on these factors, accordingly, the proposed model can efficiently find a reasonable solution that adapts to the existing situation to avoid any failure of organizational management. The proposed system is built based on a decision support system (DSS) with inputs that represent the influencing factors and an output that represents feedback on the method of management. In this paper, the proposed change management model has been verified, and the results have been reported accordingly.
\end{abstract}

Keywords-Change Management; External Environment; Internal Environment; Decision Support System (DSS)

\section{INTRODUCTION}

Change management is a transformation model that deals with the changing elements in an organization. Vlados [1] defined change management as "the forms and ways to design, implement, control, evaluate, and assimilate changes". In the business management field, significant changes should be implemented as a response to the changing elements in an organization [2], which are carried out using the change management models. With the rapid changes in the world nowadays, change management becomes crucial to every organization. Generally, a change management model comprises a set of processes that are required to achieve the desired outcome and to deal with the management aspects that are affected by the change. In terms of elements, change management concerns about people, processes, and culture [3]. Change management also covers other related elements, such as the strategic direction and the personal development of the staff [4]. In terms of process, change management implements planning, initiating, realizing, controlling, and finally stabilizing the change processes on both, corporate and personal level.

Although change management has been around for a while, it becomes more popular recently for its role in initiating significant changes to work procedure and culture in rapidly changing fields, such as pollution prevention, fertilizer, water resource, energy, raw materials management, pesticide residues, etc. [5]. According to Graetz [6] "increasing globalization, deregulation, the rapid pace of technological innovation, a growing knowledge workforce, and shifting social and demographic trends, few would dispute that the primary task for management today is the leadership of organizational change". Accordingly, the needs for change management approach is increasing nowadays like no time before. The organizational change is not a rare event nowadays, but it is an ongoing process, which makes the models of 'business as usual' becomes insignificant to most organizations. The demands for change management models are increasing day by day, and the developed approaches are filling this gap with inventions of various models.

Various models for change management have been developed to address the change in the environment controlling the organizations. The current researches have created formal environmental management models. Earlier models for change management, such as the awareness, desire, knowledge, ability and reinforcement (ADKAR) model, Kotter's model, Bridge's model, McKinsey's model and Lewin's model [7], focused on specific feature, element or process, such as the planning, human adaptation to change or the theoretical characteristics of the change management process. While the recent approaches that are developed for change management focus on analyzing the factors that influence the change processes, moreover, these approaches provide suitable frameworks to be adopted in the implementation of the change based on these factors [8]. Accordingly, a set of predetermined factors are established, these factors are monitored, and the suitable management method is then adapted based on these factors. Overall, these models bridge the gap between motivation, planning, and implementation. These models are highly significant as the organizational change is not a rare event anymore, but it is an ongoing process, and the 'business as usual' model becomes insignificant to most organizations.

Kolk and Mauser [9] gave an overview of the process by which the development of such environmental management models can be implemented. Besides, model analysis and model evaluation in term of characteristics, strengths, and weaknesses have been discussed and clarified. Although the change management models have been studied extensively, automatic approaches for change management is still immature. The computational provision of the change management models is limited and of rule-based basis. Rulebased depends on inputs based on the pre-determined change 
factors and selects among pre-determined actions encoded in the rules as the proper response for the change factors. Although the rule-based approach is easy to be interpreted by the user, it is erroneous as it required accurate rules based on the human expertise, which could not be accommodated when the changes are taken places rapidly. Accordingly, intelligent change management model needs to be developed based on machine learning approach.

In this paper, an intelligent and adaptive model for change management is developed based on a decision support system (DSS) with inputs that represent the influencing factors and an output that represents feedback on the method of management. The proposed approach takes into consideration all the positive and negative effects (factors) that may take place at any time and any place internally (internal factors) or externally (external factors). In this way, change management is carried out using a practical way immediately as responding to any changes in external and internal environmental changes. Using this approach has been hypothesized to ensure that the correct selection is guaranteed. The rest of this paper is organized as follows: Section 2 presents the related work. Section 3 presents the factors of the change management. In Section 4, the details of the proposed approach are described. Section 5 is devoted to the evaluation, and finally, Section 6 is a conclusion.

\section{RELATED WORK}

Atomization the business process management is critical to provide semantics to the business process and systemize the process. In this aspect, Figueiredo and de Oliveira [10] used ontology to represent the business process. According to Figueiredo and de Oliveira [10] "ontologies conceptualize and organize the information that is embedded and unstructured in the business processes and that must be explored. They structure the implicit knowledge that is present in the business processes, enabling the understanding of this knowledge by machine". Accordingly, the business process can be analyzed automatically based on the utilized ontology, anomalies can be detected and the changes can be conducted manually based on the detected changes.

Sarno and Sinaga [11] used ontology to capture the business process anomalies in comparison with the company's principles. Unlike the approach that is proposed by Figueiredo and de Oliveira [10], Sarno and Sinaga [11] approach detects anomalies automatically. Yet, the change management is implemented manually based on the captured anomalies. Ariouat et al. [12] developed an ontology for business process management based on three perspectives, these are behavioural organizational, and social. Rules are defined to deduce knowledge from the constructed ontology and changes can be deduced in similar ways. Similar other approaches based on ontology and knoweldge extraction have been proposed to autmatize the buisness process [13, 14]. Yet, these systems required human intervention to response to the changes.

Oriol et al. [15] proposed a rule-based model for business process management with constraints violation checking. The input to the model are the business process that are represented in UML, and the output is repair activity. Overall, based on the reviewed literature, the change management process is implemented as a manual step after analyzing the business process.

The computational provision of the change management models is limited. The existing change management models can be characterized as a rule-based approach that derived suitable actions based on a set of criteria. The developed approaches used different factors and implemented different actions. Ayhan et al. [16] proposed a multi-agent system for change management, in which agents are monitoring the changes in an organization, sharing the change information and cooperating their response. Agents are responsible for identifying the change factors, such as the capabilities of the organization to change and selects among pre-determined actions, the proper response based on the change factors.

\section{Change MANAGEMENT FACTORS}

In order to quantify the factors to be considered in the change management models, Kuipers et al. [17] reviewed the existing literature on the change management and identified four factors by which change is influenced and through which the change management is taking place, these are context, content, process, and outcomes.

The context refers to the internal and external factors, such as policies, political and economic changes. As a response to the context, Macleod and By [18] studied the effects of the context on the change management of public sector organizations and analyzed the benefits of using historical context data in make decisions about the management techniques in public sectors. Similarly, Modell [19] addressed the context influence in a healthcare organization. While De Boer et al. [20] studied the context of educational change management. These studies illustrated the influence and benefits of the context using use-cases with context-related data analysis. The content refers to the strategies of the organization, such as the management structure and hierarchy [21]. The existing literature on content-based change management focused on the effects of policies in public sectors that are related to the public organization. Schout [22] discussed and criticized the existing change management techniques in relation with the change in policies and regulations within public sector organization and highlighted the benefits of reflecting the change management based on the details change in the policies as parallel to using the historical data in change management technique. The processes refer to the periodically organizational process, duties, and roles. Erakovic and Powell [23] proposed three ways for change management based on the process influence; these are incremental change management, radial and reductive. The outcomes refer to the experiences gained by the change and which should contribute to the management of future changes [24]. A literature review on the change management outcomes showed that the outcomes of the change management are four types, these are readiness for change, commitment to change, openness to change and cynicism about organizational change [25]. Various studies have focused on change management concerning the outcome. Paul Battaglio Jr and Condrey [21] studied the change management from an outcome perspective in the public sector, while Lindquist [26] studied the outcome in change management in the private sector. 
Overall, change management in public, and private sectors are equal in recent studies [27, 28]. The theoretical models for change management are presented in the literature, yet there is a need to develop an automatic change management technique for general purpose based on analyzing and processing previous data from the factors above.

\section{THE PROPOSED APPROACH}

In order to develop a comprehensive environmental management model in a rapidly changing environment, a data mining approach based on DSS is proposed in this paper. The proposed intelligent and adaptive model for management in the rapidly changing environment uses various components that are integrated to produce consistent and acceptable decisions as given in Fig. 1, these components are the external environment factors, the internal environment factors, decision support system and the intelligent change management process. The proposed model is developed by determining the influenced factors, then, identifying the DSS resources and finally setting the overall process by which the decision-making is implemented.

\section{A. External and Internal Environmental Factors}

Any organization is related to a community and the surrounding environment from which it obtains the resources and to which it supplies products and services. In details, without the financial recourses and human resources, the organization seize to exist. Moreover, an organization has to obey and follows legalizations and other requirements imposed by the local government, as well as following the trends of the market and competitors. Besides, organizations must respond to any political change inside or outside the country. Accordingly, an organization is established based on a mutual relationship with its environment social, financial, regulations and market status and conditions. Overall, the factors of the external environment, as listed in Table I, which are considered by the proposed model are the political, social and organizational bylaws, the economic, competition, and investment requirements and the environment and ecology requirements. The internal environment factors are human resources, budget and financial situation, and the products/ services factor.

\section{B. Decision Support System (DSS) Resources}

The DSS of the proposed approach is built based on the following resources: the organizational database that contains information about the internal factors, information resources for the external factors, which are obtained using information retrieval from the internet, planning studies and marketing studies, as listed in Table II. The information systems play a significant role to perceive the environmental changes and to act in the right way. Information systems are used to collect environmental data and to identify the external and internal changes that urge the organization response. New coming technologies, new products and changing of the public tastes and values put strains on an organization's culture, politics, and people. The inertia built into an organization's standard operating procedures, the political conflict raised by changes to the existing order, and the threat to closely held cultural values typically inhabit organizations from making significant changes. Environments usually change much faster than organizations. Accordingly, the organization has to adapt to a rapidly changing environment by continuously collecting information about the surrounding environment.

Accordingly, in the proposed system, the external factors, which are determined in the previous subsection, are controlled by a set of search terms, and statistics about the retrieval information from the internet are saved and used for decisionmaking. The values of the internal factors are managed internally by the organization and the saved in the database system, which is accessed by the DSS. The marketing and planning studies are represented as another set of factors. All together forms a timely changed feature vector that is used to make the suitable action and adapt to the environmental change in the proposed change management system, as illustrated in the example given in Table III.

TABLE. I. EXTERNAL AND INTERNAL ENVIRONMENTAL FACTORS

\begin{tabular}{|l|l|l|l|}
\hline Index & Factor & Index & Factor \\
\hline FM1 & Political & FM6 & Investment requirements \\
\hline FM2 & Social & FM7 & Environment and Ecology \\
\hline FM3 & Organization bylaws & FM8 & Human resources \\
\hline FM4 & Economic & FM9 & Budget \& financial situation \\
\hline FM5 & Competition & FM10 & Products/services \\
\hline
\end{tabular}

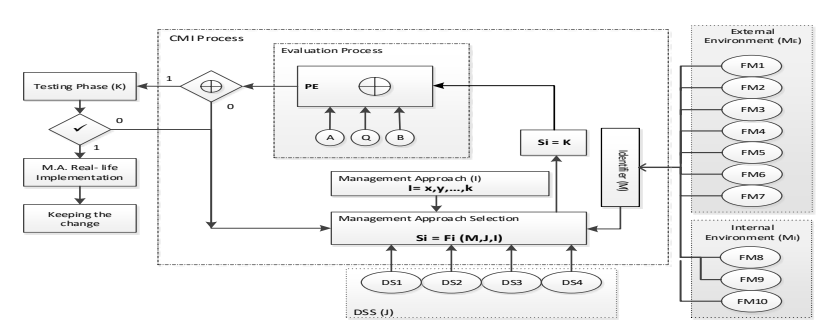

Fig. 1. An Intelligent and Adaptive Model for Change Management.

TABLE. II. DECISION SUPPORT DECISION ELEMENTS

\begin{tabular}{|l|l|}
\hline Index & Element \\
\hline DS1 & Internet (For external factors) \\
\hline DS2 & Database (For internal factors) \\
\hline DS3 & Marketing Studies \\
\hline DS4 & Planning Studies \\
\hline
\end{tabular}

TABLE. III. EXAMPLE FEATURE VeCtOR

\begin{tabular}{|l|l|}
\hline Factor & Change \\
\hline Political & Minor Change \\
\hline Social & No Change \\
\hline Bylaws & No Change \\
\hline Economic & Major Change \\
\hline Competition & No Change \\
\hline Investment & Minor Change \\
\hline Environment & No Change \\
\hline Human & No Change \\
\hline Budget & Major Change \\
\hline Product & No Change \\
\hline Marketing & No Change \\
\hline Planning & No Change \\
\hline
\end{tabular}




\section{Model Description}

The cooperation of the previous factors leads to determine the decision to be made for change management, which put the organization on the right path and avoids any failure of the business. The proposed model for change management process inputs, which are represented by the discussed factors, and produce the outputs as a decision to be made. The input variables are aggregated in a hierarchy of factors with three levels; the bottom level involves all the features discussed previously. In the second level, the variable $M$ combines all the external and internal factors, which are: political factor, social factor, organizational bylaws factor, economic factor, competition factor, investment factor, and environment factor. Besides, this variable combines the internal factors, which are human resources, budget and product/service factors. Variable $J$ combines the following: planning studies, marketing studies and databases. Finally, the variable $I$ refer to the method(s) of management, which can be centralized, distributed, etc.

The processing stage of the system includes a management method (approach) selection and evaluation process. The management approach selection step used the inputs, which are represented as $M, J$ and $I$ and to select the best method that will be suitable to a current situation of organization taking into account based on the inside and the outside effects. An intermediate result is that the management selection step will go through the evaluation process. The evaluation process is a subsystem that measures and evaluates the selected management approach based on AQB criteria, which are:

- A: stands for the employees' level of acceptance to apply a new management approach measured in percentage.

- Q: stands for quality measurement, and it refers to the percentage by which the new management approach can meet the quality standard requirements in a given organization.

- B: stands for a budget of an organization and refers to the percentage by which the budget can support the selected approach of management.

The output of the evaluation process can be negative or positive. In a negative case, a loopback step will be carried out to select another management approach while in a positive case, the selected approach for change management will go through a testing stage (phase) for a while to ensure that the selected approach is a right choice otherwise; the loopback process will take place. After a positive result of the testing phase, a select approach of organizational management will be confirmed.

\section{EVALUATION AND RESUlTS}

In the evaluation process, an online survey is conducted to establish a dataset that is used to evaluate to what extent the proposed model can fit with the change management in different organization. The target organizations were experts who are working in the education field, a telecommunication corporation and banking. Although these fields do not cover all organizations that require change management, we believe the results can be used to validate the proposed approach. The survey involves the representation of the variables $\mathrm{M}, \mathrm{J}$, and I with their related factors. Content Validity Index (CVI) is used for model evaluation [29]. The number of experts that are considered, according to the literature is $2-20$, in this study 18 experts were contributed to the validation of the model [29]. Before filling in the survey, a brief on the developed model was given to the experts. CVI is calculated as the percentage of scores of 3 or 4 to the total number of scores (number of questions in the survey). Lynn [30] suggests that above 0.78 is accurate results with this number of experts. The complete questioner is given in Appendix A. The results of the survey are given in Table IV.

Out of the 18 raters, 8 raters rates the correctness and the applicability with scale 4 . The rest of the raters have awarded mixed of scale 3 and scale for the two criteria. Helpfulness comes in the second order among criteria. All the rates have rated the helpfulness with mixed of scale 2, scale 3 and scale 4. The low rates were awarded for attractiveness and easiness. To justify this issue, it was realized that the rates does not know what DSS is and how such system could be implemented. Accordingly, easiness can only be evaluated with a full empirical study in the future.

As for the testing phase, the experiments depend on the following factors:

- Human resources factor (A) that measures the acceptance rate of the new management approach among human resources in an organization.

- Budget and economic situation of an organization factor (B), which involves questioning about whether the budget and economic situation can support and endure the consequences of applying a new management approach.

- Quality factor (Q), a new approach of management should achieve minimum requirements of quality issues within an organization.

To explain the evaluation process that is proposed, the system supposes represent each of the factors, A, Q and B using 2-bit code and the combination of these bits represents the percentage of the effects on the change management process. This percentage reflects the performance of the system for change management as the following:

- $00: 0 \%$

- $01: 25 \%$

- $10: 50 \%$

- $11: \geq 75 \%$

The results of the evaluation process based on a constructed dataset based on the survey results are conducted and after careful analysis, it was concluded that for the input factors with a minimum value of $50 \%$ for $\mathrm{B}$ and $\mathrm{Q}$ while a minimum of $0 \%$ for the A factor, in some particular cases lead to acceptance of the management style being followed. Table $\mathrm{V}$ illustrates the AQB factors presented in a combination of 6 bits $(2$ bits for each factor) along with results of the evaluation process in a proposed model. 
TABLE. IV. SURVEY RESULTS

\begin{tabular}{|l|l|}
\hline Element & Value \\
\hline Number of raters & 18 \\
\hline Average pairwise percentage & $70 \%$ \\
\hline Total number of answers & 18 (Experts) $* 15$ (Questions) $=270$ \\
\hline Total number of scale 1 answers & 28 \\
\hline Total number of scale 2 answers & 30 \\
\hline Total number of scale 3 answers & 122 \\
\hline Total number of scale 4 answers & 90 \\
\hline CVI & $\mathbf{0 . 7 8 5}$ \\
\hline
\end{tabular}

TABLE. V. EVALUATION RESUlts

\begin{tabular}{|l|l|l|}
\hline AQB & Output & Results \\
\hline 000000 & 0 & $\mathrm{x}$ \\
\hline 000001 & 0 & $\mathrm{x}$ \\
\hline$\ldots \ldots \ldots$. & $\ldots \ldots \ldots$ & $\ldots \ldots \ldots$ \\
\hline 001011 & 1 & $\checkmark$ \\
\hline 001010 & 1 & $\checkmark$ \\
\hline$\ldots \ldots \ldots$ & $\ldots \ldots \ldots$. & $\ldots \ldots \ldots$ \\
\hline 100000 & 0 & $\mathrm{x}$ \\
\hline$\ldots \ldots \ldots$. & $\ldots \ldots \ldots$ & $\ldots \ldots \ldots$ \\
\hline 101010 & 1 & $\checkmark$ \\
\hline 111111 & 1 & $\checkmark$ \\
\hline
\end{tabular}

\section{CONCLUSION}

In this paper, a new intelligent and adaptive model for change management has been developed to carry out change management based on a set of influencing factors and a decision-making process that uses a decision support system (DSS). All the internal and external factors of the change management were taken into account. The output of the proposed model is either a negative or a positive indication. In a negative case, a loopback step can be carried out to select another management approach while in a positive case, the selected approach for change management will go through a testing stage (phase) for a while to ensure that the selected approach is a right choice otherwise. The pilot experiments of the proposed model show its effectiveness in identifying the correct/wrong decision for change management. The correctness and the applicability of the proposed approach were proved to be satisfied. Out of the 18 raters, 8 raters rates the correctness and the applicability with scale 4 . The rest of the raters have awarded mixed of scale 3 and scale for the two criteria. The CVI of the pilot study was 0.78 .

In the future, some cases will be experimentally implemented to show the efficiency of the model, an enhanced algorithm that explains the work of the proposed will also be developed. The goal of the future work will be enhancing the rates of the attractiveness and easiness criteria.

\section{REFERENCES}

[1] C. Vlados, Change Management and Innovation in the 'Living Organization': The Stra. Tech. Man Approach. Management Dynamics in the Knowledge Economy, vol. 7, no. 2, 2019, pp. 229-256.

[2] H. Kerzner and H.R. Kerzner, Project management: a systems approach to planning, scheduling, and controlling, John Wiley \& Sons, 2017.
[3] M. Rosemann and J. vom Brocke, The six core elements of business process management, in Handbook on business process management, Springer, 2015, pp. 105-122.

[4] A. Alkhafaji and R.A. Nelson, Strategic management: formulation, implementation, and control in a dynamic environment, Routledge, 2013.

[5] Z. Malek, P. H. Verburg, I. R. Geijzendorffer, A. Bondeau, and W. Cramer, Global change effects on land management in the Mediterranean region, Global Environmental Change, vol. 50, 2018, pp. 238-254.

[6] F. Graetz, Strategic change leadership, Management decision, vol. 38, no. 8, 2000, pp. 550-564.

[7] S. T. Hussain, S. Lei, T. Akram, M. J. Haider, S. H. Hussain, and M. Ali, Kurt Lewin's change model: A critical review of the role of leadership and employee involvement in organizational change, Journal of Innovation \& Knowledge, vol. 3, no., 3, 2018, pp. 123-127.

[8] S. Oreg, J. M. Bartunek, G. Lee, and B. Do, An affect-based model of recipients' responses to organizational change events, Academy of Management Review, vol. 43, no. 1, 2018, pp. 65-86.

[9] A. Kolk and A. Mauser, The evolution of environmental management: from stage models to performance evaluation, Business strategy and the environment, vol. 11, no. 1, 2002, pp. 14-31.

[10] L.R. Figueiredo and H.C. de Oliveira, Automatic Mapping of Business Process Models for Ontologies with an Associated Query System, International Conference on Enterprise Information Systems, 2018.

[11] R. Sarno and F.P. Sinaga, Business process anomaly detection using ontology-based process modelling and multi-level class association rule learning, International Conference on Computer, Control, Informatics and its Applications (IC3INA), 2015.

[12] H. Ariouat, C. Hanachi, E. Andonoff, and F. Benaben, A conceptual framework for social business process management, Procedia Computer Science, vol. 112, 2017, pp. 703-712.

[13] J. B. Gassen, J. Mendling, A. Bouzeghoub, L. H. Thom, and J. P. M. de Oliveira, An experiment on an ontology-based support approach for process modeling, Information and Software Technology, vol. 83, 2017. pp. 94-115.

[14] K. Kluza, K. Kaczor, G. J. Nalepa, and M. Ślażyński, Opportunities for business process semantization in open-source process execution environments, Federated Conference on Computer Science and Information Systems (FedCSIS), 2015.

[15] X. Oriol, G. De Giacomo, M. Estañol, and E. Teniente, Automatic business process model extension to repair constraint violations, International Conference on Service-Oriented Computing, 2019.

[16] M.B. Ayhan, M.E. Aydin, and E. Öztemel, A multi-agent based approach for change management in manufacturing enterprises, Journal of Intelligent Manufacturing, vol. 26, no. 5, 2015, pp. 975-988.

[17] B. S. Kuipers, M. Higgs, W. Kickert, L. Tummers, J. Grandia, and J. Van der Voet, The management of change in public organizations: A literature review, Public administration, vol. 92, no.1, 2014, pp. 1-20.

[18] C. Macleod and R.T. By, Organizational change management in public services: Key findings and emerging themes, Managing Organizational Change in Public Services, Routledge. p. 263-271, 2012.

[19] S. Modell, Performance measurement and institutional processes: a study of managerial responses to public sector reform, Management Accounting Research, vol. 12, no. 4, 2001, pp. 437-464.

[20] H.F. De Boer, J. Enders, and L. Leisyte, Public sector reform in Dutch higher education: The organizational transformation of the university, Public Administration, vol. 85, no. 1, 2007, pp. 27-46.

[21] R. Paul Battaglio Jr and S.E. Condrey, Reforming public management: Analyzing the impact of public service reform on organizational and managerial trust, Journal of Public Administration Research and Theory, vol. 19 , no. 4 , 2009, pp. 689-707.

[22] A. Schout, Organizational learning in the EU's multi-level governance system, Journal of European Public Policy, vol. 16, no. 8, 2009, pp. 1124-1144.

[23] L. Erakovic and M. Powell, Pathways of change: organizations in transition, Public Administration, vol. 85, no., 1, 2006, pp. 31-58. 
[24] A.A. Armenakis and A.G. Bedeian, Organizational change: A review of theory and research in the 1990s. Journal of management, vol. 25, no., 3, 1999, pp. 293-315.

[25] Choi, M., Employees' attitudes toward organizational change: A literature review. Human Resource Management, vol. 50, no. 4, 2011, pp. 479-500.

[26] E., Lindquist, Organizing for policy implementation: The emergence and role of implementation units in policy design and oversight, Journal of Comparative Policy Analysis, vol. 8, no. 4, 2006, pp. 311-324.
[27] W. J. Kickert, Managing emergent and complex change: The case of dutch agencification, International Review of Administrative Sciences, vol. 76, no. 3, 2010, pp. 489-515.

[28] P. Klarner, G. Probst, and R. Soparnot, Organizational change capacity in public services: The case of the World Health Organization, Journal of Change Management, vol. 8, no. 1, 2008, pp. 57-72.

[29] R. K. Gable and M. B. Wolf, Instrument development in the affective domain: Measuring attitudes and values in corporate and school settings, vol. 36, Springer Science \& Business Media, 2012.

[30] M. R. Lynn, Determination and quantification of content validity, Nursing research, vol. 35 , mo. 6, 1986, pp. 382-386.

\section{APPENDIX A}

The goal of this survey is to evaluate a model of change management through a set of variables and its related factors. The target of the survey is experts in education, telecommunication business, and banking. We hope that by conducting this survey, we will be able to capture your judgment/opinion about the model developed.

Instruction: Please state the extent to which you agree or disagree with the following statements (tick one per statement), where:

\begin{tabular}{|c|c|c|c|c|}
\hline 1 is Strongly disagree & \multicolumn{4}{|c|}{2 is Disagree } \\
\hline 3 is Agree & \multicolumn{4}{|c|}{4 is Strongly agree } \\
\hline \multirow{2}{*}{ Q1. CORRECTNESS } & SDIS & DIS & $\mathrm{AG}$ & SAG \\
\hline & 1 & 2 & 3 & 4 \\
\hline A. The variables of the proposed model are correctly identified & O & $\mathrm{O}$ & O & O \\
\hline B. The factors related to each variable are correctly identified & $\mathrm{O}$ & $\mathrm{O}$ & $\mathrm{O}$ & O \\
\hline C. The linkage between the factors and the variable are valid & O & O & O & O \\
\hline D. The model is conceptually valid & O & O & $\mathrm{O}$ & O \\
\hline \multirow{2}{*}{ Q2. APPLICABILITY } & SDIS & DIS & AG & SAG \\
\hline & 1 & 2 & 3 & 4 \\
\hline E. The utilized variables can be used to guide the change management process & $\mathrm{O}$ & O & O & $\mathrm{O}$ \\
\hline $\begin{array}{l}\text { F. The factors that are considered cover all the features that influence the change } \\
\text { management }\end{array}$ & O & O & O & O \\
\hline $\begin{array}{l}\text { G. The linkage between the factors and the variables can be used to model the change } \\
\text { management factors }\end{array}$ & O & O & O & O \\
\hline H. The model is applicable for any change management process & O & O & O & O \\
\hline \multirow{2}{*}{ Q3. HELPFULNESS } & SDIS & DIS & AG & SAG \\
\hline & 1 & 2 & 3 & 4 \\
\hline $\begin{array}{l}\text { I. The model helps managers to evaluate the management decision in the change } \\
\text { management process }\end{array}$ & O & O & O & $\mathrm{O}$ \\
\hline $\begin{array}{l}\text { J. The model helps managers to understand the factors that are considered for the } \\
\text { change management process }\end{array}$ & $\mathrm{O}$ & $\mathrm{O}$ & $\mathrm{O}$ & O \\
\hline \multirow{2}{*}{ Q4. ATTRACTIVENESS } & SDIS & DIS & AG & SAG \\
\hline & 1 & 2 & 3 & 4 \\
\hline $\begin{array}{l}\mathrm{K} \text {. The model is widely applicable to evaluate the management decision in the change } \\
\text { management process }\end{array}$ & O & O & O & O \\
\hline $\begin{array}{l}\text { L. The model is widely applicable to understand the factors that are considered for the } \\
\text { change management process }\end{array}$ & O & O & O & O \\
\hline $\begin{array}{l}\text { M. The model is widely applicable to provide feedback about the organization } \\
\text { change management process }\end{array}$ & 0 & O & 0 & O \\
\hline \multirow{2}{*}{ Q5. EASYNESS } & SDIS & DIS & AG & SAG \\
\hline & 1 & 2 & 3 & 4 \\
\hline N. The model is easy to be understood & $\mathrm{O}$ & $\mathrm{O}$ & $\mathrm{O}$ & $\mathrm{O}$ \\
\hline O. The model is easy to be applied & $\mathrm{O}$ & $\mathrm{O}$ & $\mathrm{O}$ & $\mathrm{O}$ \\
\hline
\end{tabular}

